\title{
DAMAGE BETWEEN WESTPORT AND GREYMOUTH
}

\author{
A. D. Smith*
}

Except for the adjoining coal-mining townships of Runanga and Dunollie, five miles north of Greymouth, buildings in the fifty mile long stretch of coast between westport and Greymouth occur only in small groupings widely scattered along the coastal highway. Runanga and Dunollie are located two miles inland, and are situated partly on soft and saturated soil.

Elsewhere along the coast, the small groups of buildings, generally, are on small areas of flat land between a rugged rocky coastline and steep hills. The hills rise up into the Paparoa Range of mountains, with peaks of 4000 to 5000 feet elevation. The range effectively separates the narrow coastal strip of habitable land from the inland valley of the Grey and Inangahua Rivers.

Along the coast, outcrops of rock are interspersed with stretches of steep hillslope. The country, although steep, generally showed no evidence of the effects of earthquake. There was no notable evidence of fissuring or cracking of ground, except subsidence of the fill at bridge approaches. However between Punakaiki and Westport some landslips had occurred, but the relative contribution of earthquake and rainfall is not known to the author. Only in one case had a building clearly been damaged by landslip as a result of earthquake. A holiday bach, of timber, had been built on the extreme edge of a coastal cliff. Due, perhaps basically to a condition arising from prior erosion of the sea, the earthquake caused a portion of land to drop away from beneath the building. The building was pulled to safety and erected on another site.

\section{Buildings}

Buildings in the townships of Runanga and Dunollie consist mainly of dwellings and shops. Most buildings have wood framing and outer sheathing, although some of the newer buildings have walls of concrete blockwork. Many dwellings are 40 to 60 years old and are poorly maintained. Most of the old buildings have foundations of timber piles which, in the damp soil, have deteriorated over the years. Shortly prior to the earthquake, floods had left the lowest areas of the township waterlogged. That increased several existing subsidences, leaving obscure the later contribution of earthquake in initiating or increasing subsidences. This issue could be examined in the light of all available evidence:- last date of painting weather boards or of papering interiors; existing prior repairs or patching; the appearance of cracks and gaps, whether fresh or dirty, and perhaps containing paint or moss; the similarity with other patterns of known damage; the obvious sequence of movements. Niuch damage clearly was the result of earthquake, but other damage as clearly was not the result of earthquake. The experience was found, not infrequently, that people had become conscious of earthquake "damage" and pointed out amoungst the genuine earthquake damage other incompatible things, such as cracks long filled with dirt or "instant moss" which they believed (genuinely) not to have been present on the day before the earthquake.

The movements of the old buildings on soft soils caused a large number of chimmeys to fracture, particularly of the unreinforced brick chimneys which predominate. Chimeys of precast concrete blocks suffered less damage than brick chimneys. The newer or better maintained building suffered far less damage to chimeys, lining or wall paper than the old poorly maintained buildings.

The few, well designed and constructed new buildings of reinforced concrete blockwork suffered at most only minor cracking or other damage. One dwelling on the

* Insurance Assessor, Gisborme 
coast, with wooden foundations and wooden framing, and with a wall veneer of unreinforced concrete blockwork, suffered considerable damage when one wall was shunted completely out by movements of the wooden structure.

\section{Effect of earthquake upon residents}

As it is a coal mining area, in most buildings the only heating and hot water is provided with the use of coal fires. Many residents were thus left without heating or hot water in consequence of the fracture of their chimeys. It is usual for most dwellings in Runanga and Dunollie to have at least two-sometimes three or four chimneys - and in some cases all chimeys per residence were fractured. It was not uncommon to find that families had moved out of their homes and gone to live with relatives purely for the reason that their chimneys were broken and they lacked facilities for heating and hot water.

\section{Assessment of damage}

The assessment of damage to the older buildings in the Runanga and Dunollie area was made difficult by the poor state of maintenance and general deterioration of the buildings and foundations. In many cases it was found that settlement and misalignment of buildings caused by the earthquake was only of a very minor nature compared with that which had taken place over the years.

\section{Reconstruction}

In the Runanga and Dunollie area, the Runanga Borough Council undertook the immediate organisation of the repair or rebuilding of chimeys, except for the few owners who chose to plan their own repairs. The Council arranged for the supplies of bricks and other materials, and for the availability of men, both council employees and private bricklayers. A schedule of urgent cases was prepared, with priorities for the elderly, widows and retired miners. The Council also undertook to assist, within its powers, in any way possible, the residents adversely affected by the earthquake. This resulted in a most economic and efficient method of dealing with the disaster, stabilized repair costs, ensured that the most urgent cases were completed irst, and also ensured a high standard of workmanship. The Runanga Borough Counc. I can not be too highly praised for the fine example which they set on the West Coast in the organisation and repair of disaster damage and the exceptional service given to the people in the area at the time of the earthquake. 


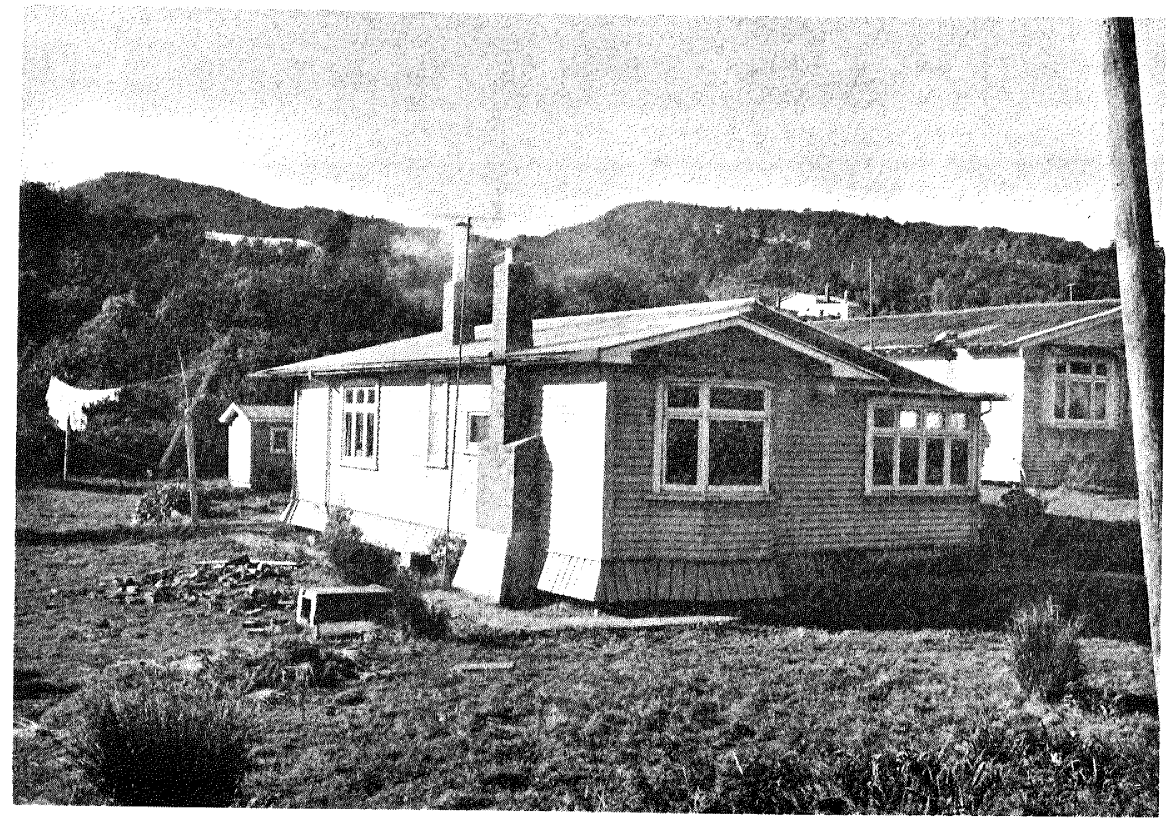

Fig. 1. House with repaired chimneys, debris still on ground

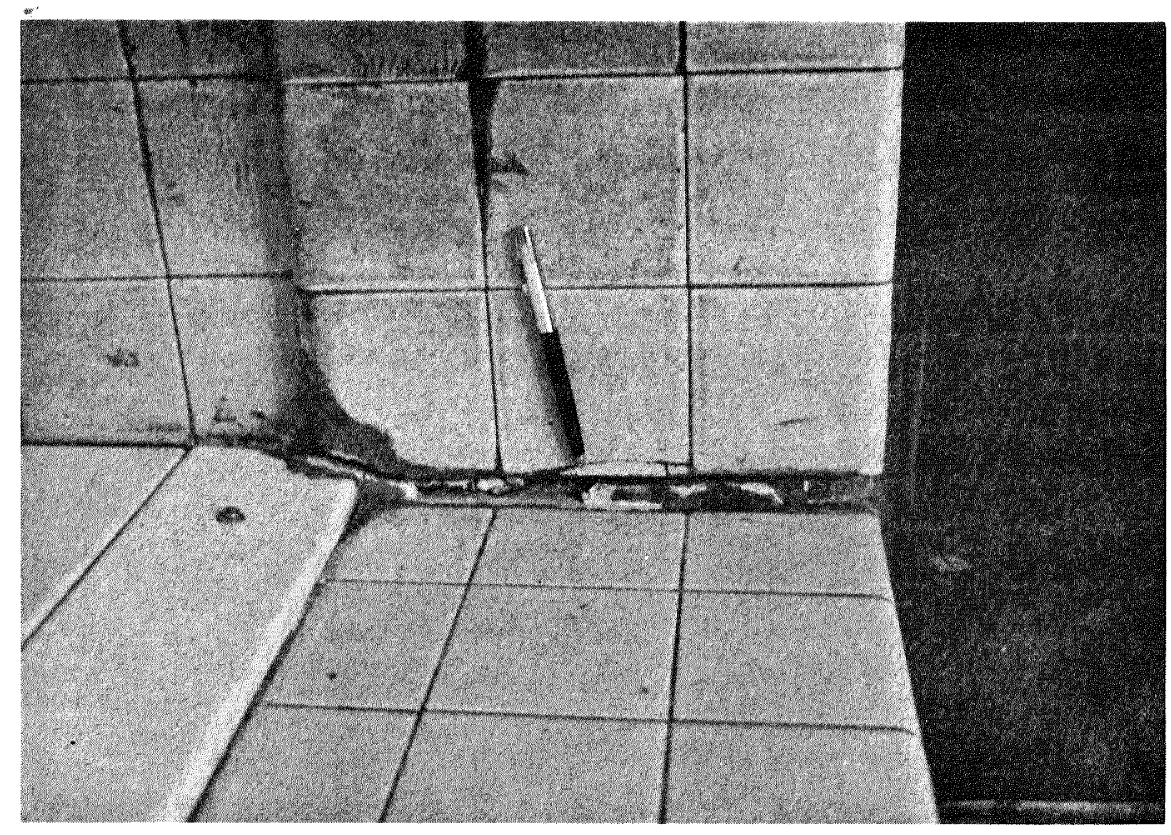

Fig. 3. Old movement \& prior evident repair at fire surround
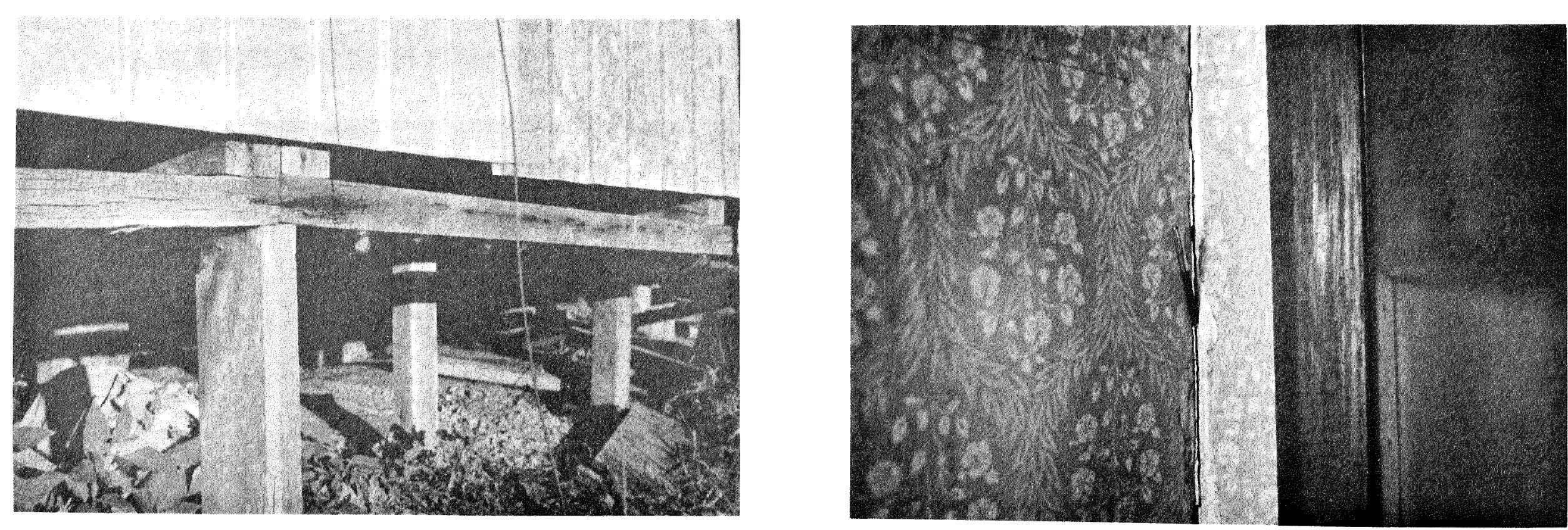

Fig. 2. Foundation and under structure of a "coastal" house

Fig. 4. Old movement and prior filling at wall junction 

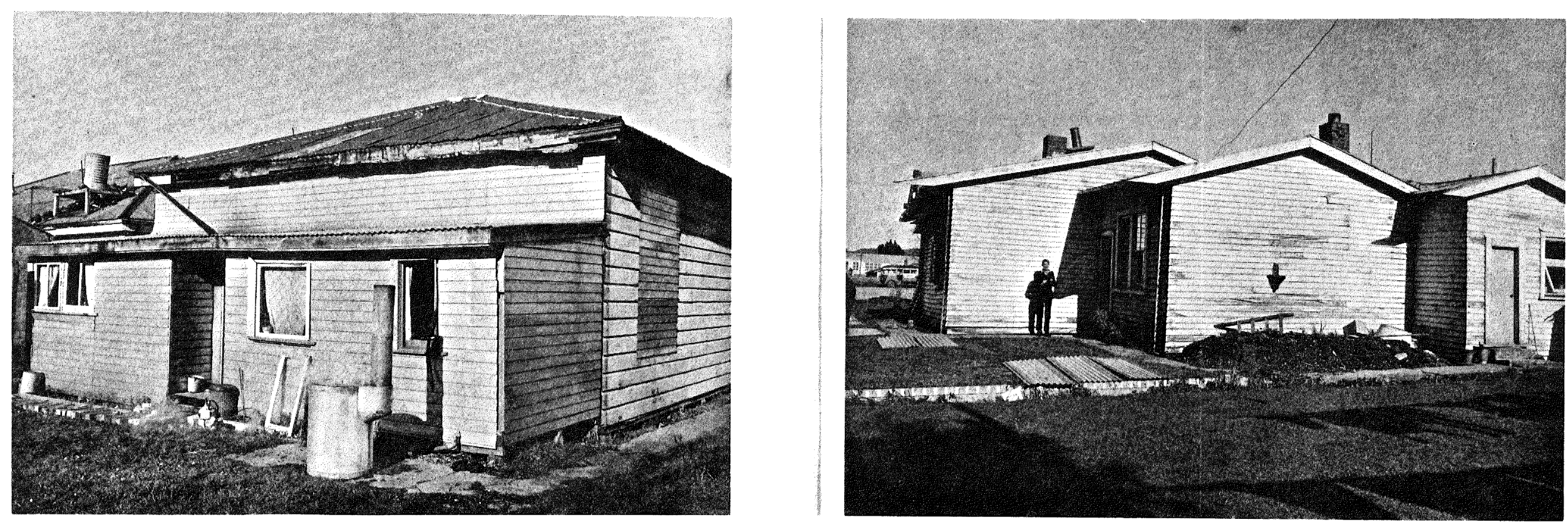

Fig. 5. Rear of dwelling, lack of maintenance, old subsidence

Fig. 7. Dwelling with irregular plan, having old settlements
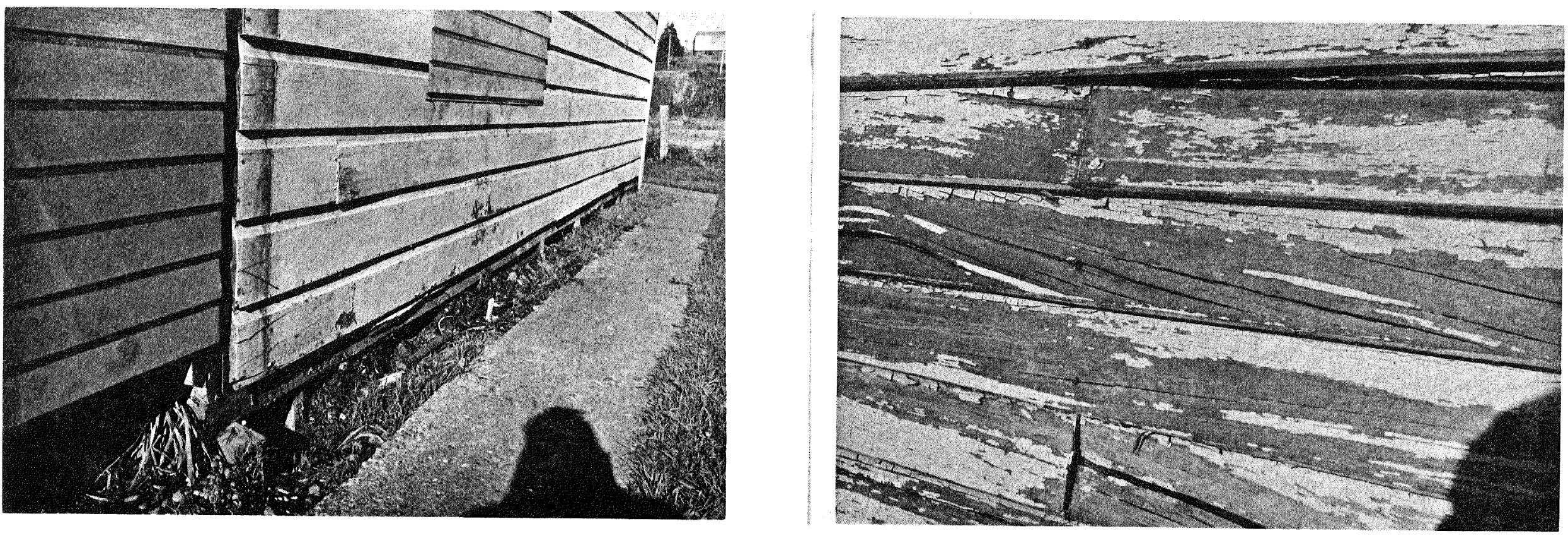

Fig. 6. Detail of view 5 , showing short piles in damp soil

Fig. 8. Detail of view 7 at arrow, showing weather boards 